\title{
TS3 - A New Technology for Efficient Timber Structures
}

\author{
Steffen Franke ${ }^{1}$ and Stefan Zöllig*2 \\ ${ }^{1}$ Bern University of Applied Sciences, Switzerland \\ ${ }^{2}$ TS3.0 AG, Switzerland
}

*Corresponding author: Steffen Franke, Bern University of Applied Sciences, Solothurn Strasse 102, 2504 Biel-Bienne, Switzerland.

\begin{abstract}
Until today, all known timber building systems allow only slabs with a uniaxial load bearing action. In the framework of a large research project a new timber slab system has been developed and already tested in first real applications. The developed slab system is designed for housing, commercial and industrial buildings. The slab system works as a flat slab carrying vertical loads biaxial and consists of timber slab elements like CLT glued together on site with a high performing butt-joint bonding technology. This technology was called Timber structures 3.0 (TS3). Several research and tests about the performance of the different slab elements and the butt-joint bonding have been performed. First structures have been built and proof the system.
\end{abstract}

Keywords: Timber flat slab; Biaxial load bearing; Butt-joint bonding; TS3

\section{Introduction}

Since 2009 the Swiss Engineering Company TS3 AG, Bern University of Applied Sciences in Biel, ETH Zurich, Timbatec, Purbond (Henkel Group) and Schilliger Holz are working together in a project called "Wooden slabs in commercial and industrial buildings". The objective of the project is the development and implementation of a biaxial load carrying timber flat slab based on elements like CLT glued together on site with a high performing butt-joint bonding technology. It was proved that it is possible to produce timber flat slabs with a column grid up to $8.00 \times 8.00 \mathrm{~m}$

and a live load of $5 \mathrm{kN} / \mathrm{m}^{2}$. This at a comparable cost to normal reinforced concrete flat slabs, but only with one-fifth of the weight and with barley no $\mathrm{CO}_{2}$ emissions. On the contrary, a large amount of $\mathrm{CO}_{2}$ is being stored within the structure. The research project has led to a market ready system. Further, the newly developed bonding connection technology opens new fields of application for timber constructions. Timber beams by almost any length or plates of almost any dimension can be produced. For example, rigid walls, floors or shells of any shape can be made. This development is so groundbreaking, and a new generation in timber construction.

\section{Evolution of Timber Structures}
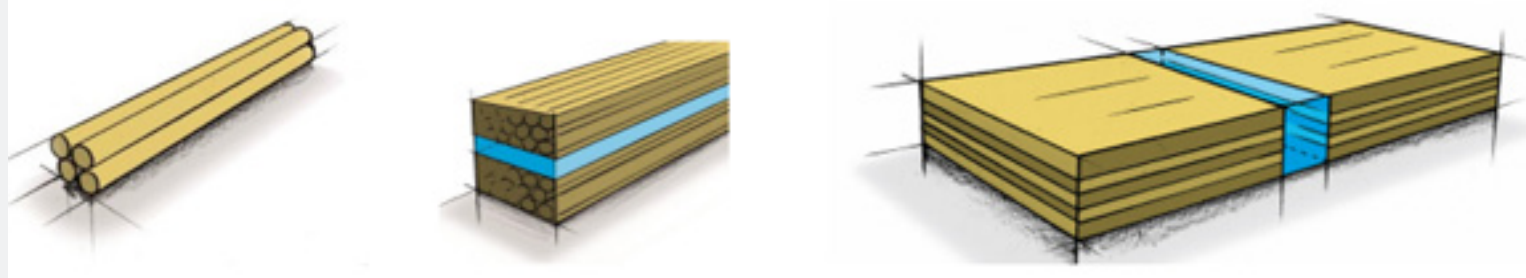

Figure 1: Trunks and beams (TS1), Glulam and CLT (TS2) and butt-joint bonding technology (TS3), f.I.t.r. 
For centuries trunks and beams have been used to build houses, which can be called the $1^{\text {st }}$ generation in timber structures (TS1.0), see Figure 1 . In the $20^{\text {th }}$ century, trees were sawn into boards, dried, planned and glued to glulam or more recently to CLT. This can by stated as the $2^{\text {nd }}$ generation in timber structures (TS2.0). With these products a structural beam can be larger and longer than a tree. Also curved structural beams are possible. The current development now allows the butt-joint bonding of fibers and therefore can lead to the 3rd generation in timber, called and patented as Timber Structures 3.0 (TS3) (Figure 1).

\section{TS3 System}

\section{General}

The aim of the newly developed technology is to be able to realize typical skeleton buildings with timber as shown in Figure 2, consisting of only glued timber elements, without using fasteners like screws, nails or metal plates. The main building parts are walls for the lateral structural system and columns and flat slabs for the vertical structural system. The main challenge is the development of a biaxial high performing load bearing timber slab. Due to constraints of prefabrication, transportation and assembly processes, it is essential to divide any type of floor plans into slab elements in an efficient way. In a parametric study the typical floor plan shown in Figure 3 has been found to be most suitable. The green elements should transfer the load biaxial to the uniaxial load bearing red elements which transfer the load to the central elements marked in blue around the columns. The blue elements are similar to the reinforced concrete flat slabs subjected to high bending moments and shear forces (Figures 2,3).

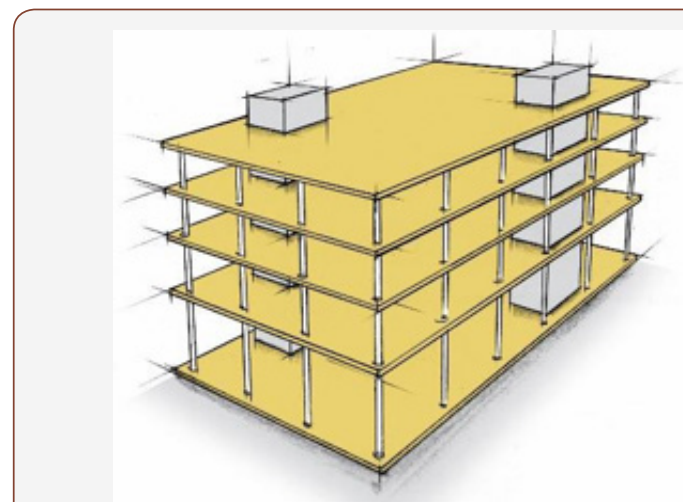

Figure 2:Typical skeleton structure.

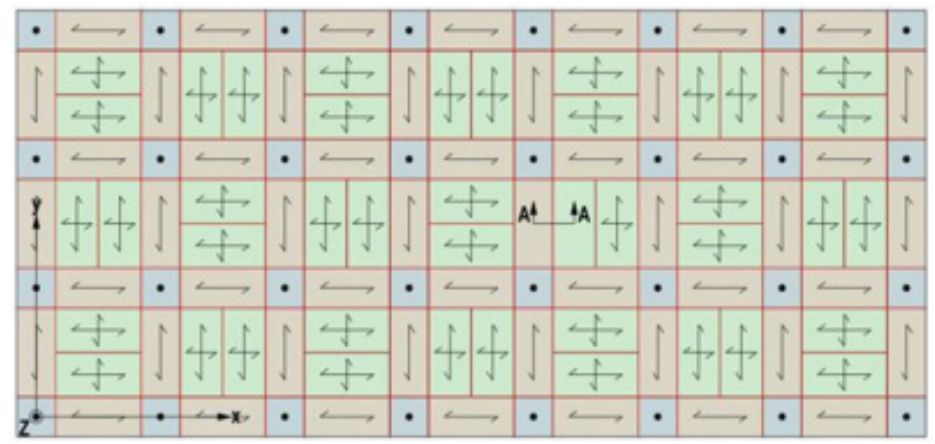

Figure 3: Possible floor plan.

\section{Column head elements}

A fundamental static issue is the highly stressed area around the column and how a reinforcement of the central slab elements against punching of the column is possible, see Figure 4 left. Investigation at the ETH Zurich on hybrid plates made of beech plywood and common spruce boards up to $400 \mathrm{~mm}$ in thickness showed that forces up to $3100 \mathrm{kN}$ can be transferred. The failure behavior showed in addition a ductile behavior. Further on, normal CLT plate elements of spruce were tested and showed enough resistances too. For the field plate elements, CLT or biaxial load transferring hollow-box systems can be used (Figure 4).
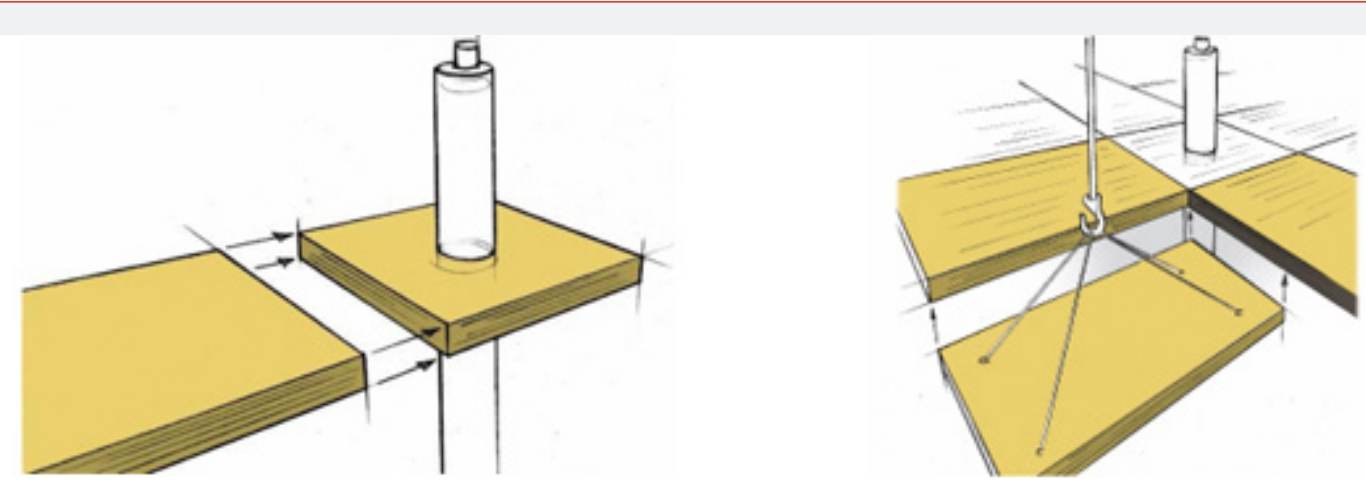

Figure 4: Placing of the column head and the field elements. 


\section{Butt-joint bonding}

To connect the slab elements to each other, various methods were evaluated. Geometric form-fitting such as a terracing or tongue and groove would lead to expensive machining time and massive consumption of material through the double plate surface in the connecting area. Due to the transverse tensile stresses at the terracing, the plates would have to be provided with additional reinforcements. Finger joints are susceptible to damage and carry low tensile stresses perpendicular to grain if they are arranged careless. Therefore, a bonded butt joint technology was envisaged. No certified adhesives existed on the market for directly bonded butt joints. Purbond AG, part of the Henkel Group, has developed a 2-component Polyurethane adhesive which can be used for the required purposes. In the first development, various geometries of bonded joints were examined. The simplest geometry to be produced was the butt joint, but also different profiles as v-rabbets and finger joints were examined. In various experimental tests it was studied which thickness of joints could be filled taking into account for different circumstances such as different temperatures or joint widths. Over 1'000 tensile tests on lamellas have been carried out. The filling procedure from below is very important, so that any air bubble moves to the top and no air pockets are created. Many parameters and different influences on building site have been investigated, like minimum and maximum joint thickness (up to $40 \mathrm{~mm}$ ), temperature, moisture content, soiling with oil or dust, movement and vibrations and different types of pre-treatment of the connecting end-grain faces. From these tests, important conditions and requirements for quality assurance were established. Also, small and large-scale fire tests have been performed in order to proof the fire resistance. The CLT-plate with bonded butt joints reached a fire resistance of 69 minutes where the CLT-plate failed due to brittle failure of the bonded butt joint.

\section{Proof of concept}

The first multi-storey apartment house was built with the Timber Structures 3.0 technology in Thun, Switzerland in 2015. Since 2019 eleven projects with 3'100 m2 have been built in Switzerland and Canada. Request of about 50 projects from all over the world are in progress. Also, outdoor test stands at the campus of ETH and the Bern University have been built. The "pavilion" in Figure 6 proofs the system with permanent loading and even severe weathering since May 2018. It is point-supported at 6 x $6 \mathrm{~m}$ span and permanently loaded with 12 ton (Figures 5,6).

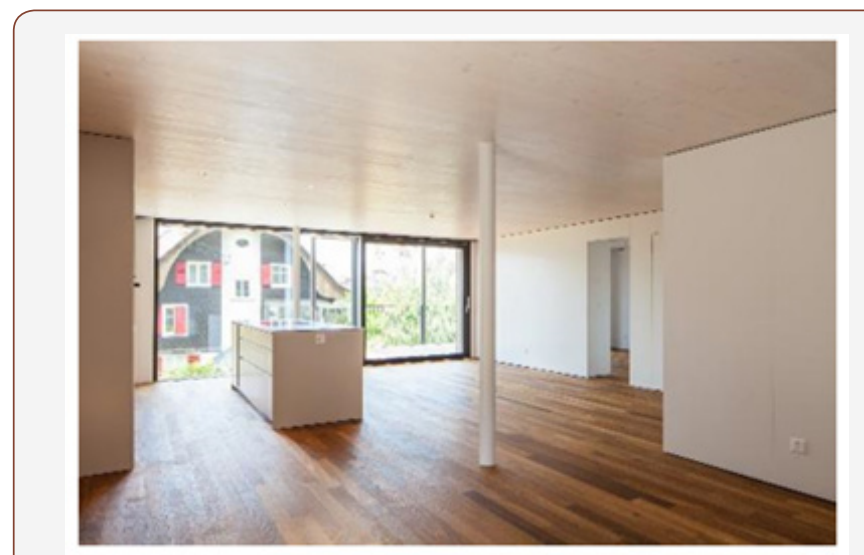

Figure 5:Timber Structures 3.0 flat slab building site of a multistorey building in Thun, Switzerland.

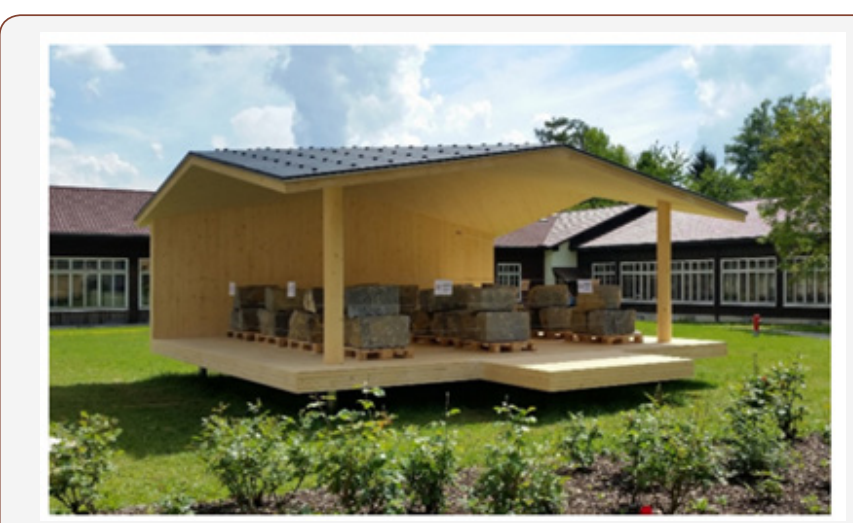

Figure 6:Outdoor test stand with a permanent loading at the Bern University of Applied Sciences.

\section{Conclusions and Outlook}

The Timber Structures 3.0 technology marks the start into a completely new way of thinking and designing of timber structures. The novel technology opens a wide field of new applications of timber structures in research, technologies and markets and strengthens the advantages in using more timber. The certifications for US, Canada and Germany are in preparation and assumed to be available in 2020. Figure 7 shows possible applications for even improved TS3 timber structures as folded or shell structures. The performance of the butt-joint for those applications are still to be investigated (Figure 7).
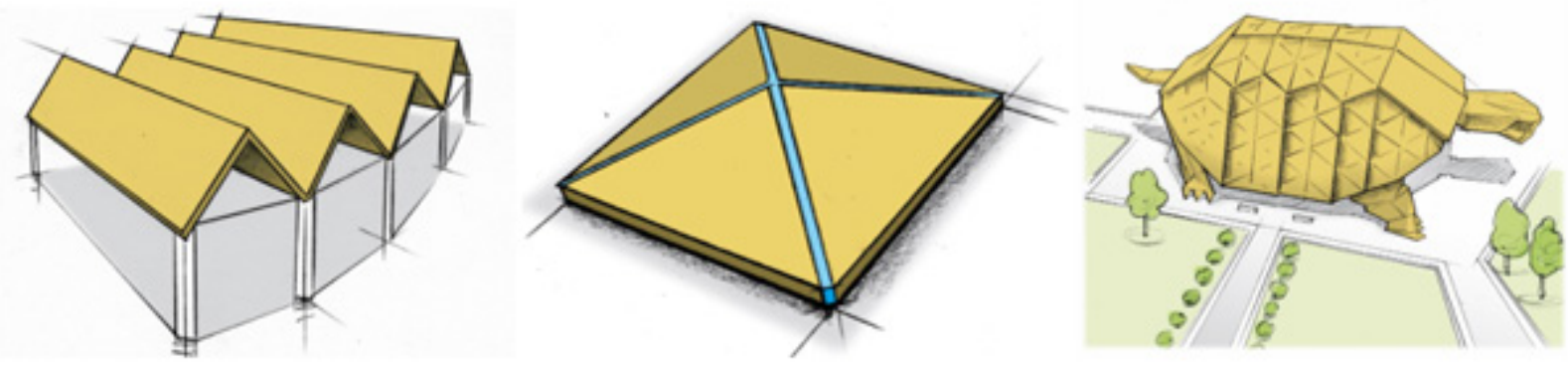

Figure 7: Placing of the column head and the field elements. 


\section{Acknowledgement and Research Partners}

The research work was proudly supported by the Commission for Technology and Innovation (CTI) of Switzerland and realized in collaboration with the research partners: Bern University of Applied Sciences (Prof. Dr. Steffen Franke), ETH Zurich (Prof. Dr. Andrea Frangi), Timbatec Holzbauingenieure Schweiz AG and
Timber Structures 3.0 AG (Stefan Zöllig), Henkel \& Cie. AG (Dr. Christian Lehringer), Schilliger Holz AG (Ernest Schilliger and Werner Leibundgut).

\section{Conflict of Interest}

No conflict of interest. 